\title{
Correlation Between BNT162b2 mRNA Covid-19 Vaccine-associated Hypermetabolic Lymphadenopathy and Humoral Immunity in Patients With Hematologic Malignancy
}

\section{Dan Cohen}

Tel Aviv Sourasky Medical Center https://orcid.org/0000-0001-8804-4806

Shir Hazut Krauthammer

Tel Aviv Sourasky Medical Center

Yael C. Cohen

Tel Aviv Sourasky Medical Center

Chava Perry

Tel Aviv Sourasky Medical Center

Irit Avivi

Tel Aviv Sourasky Medical Center

\section{Yair Herishanu}

Tel Aviv Sourasky Medical Center

Einat Even-Sapir ( $\sim$ evensap@tlvmc.gov.il )

Tel Aviv Sourasky Medical Center

\section{Research Article}

Keywords: humoral immunity, vaccination, anti-CD20, hematology, functional imaging

Posted Date: April 7th, 2021

DOI: https://doi.org/10.21203/rs.3.rs-395288/v1

License: @ (i) This work is licensed under a Creative Commons Attribution 4.0 International License. Read Full License 


\section{Abstract}

Purpose: Vaccine-associated hypermetabolic lymphadenopathy (VAHL) is frequently observed on $\left[{ }^{18}\right.$ F]FDG PET-CT following BNT162b2 administration. Recent data suggest a prominent B-cell germinalcenter (GC) response elicited by mRNA vaccines in draining lymph nodes. Thus, in this study we aimed to explore the correlation between VAHL and humoral immunity as reflected by post-vaccination serologic testing, and by comparing the incidence of VAHL between lymphoma patients treated recently with B-cell depleting therapy and those that did not.

Methods: A total of 137 patients with hematologic malignancy that had post-vaccination $\left[{ }^{18} \mathrm{~F}\right] \mathrm{FDG}$ PETCT were included (All-PET group), 86 received both vaccine doses before imaging (PET-2 group). Their VAHL status and grade on imaging were recorded. Among 102 lymphoma patients, 34 (33.3\%) were treated during the year prior vaccination with anti-CD20 antibody containing therapy. A subgroup of 54 patients also underwent serologic testing 2-3 weeks after the booster dose, and their anti-spike titers were recorded and graded as well.

Results: The overall incidence of VAHL in patients with hematologic malignancy was $31.4 \%$. The 34 lymphoma patients treated during the year prior vaccination with anti-CD20 antibody containing therapy had significantly lower rates of VAHL comparted to all other lymphoma patients (8.8\% versus $41.2 \%$ in allPET patients, $\mathrm{PV}<0.01)$. VAHL rates were $10 \%$ in patients with negative serology, $31.3 \%$ in patients with low anti-spike titers and $72.2 \%$ in patients with high anti-spike titers. The positive predictive values of VAHL were $90 \%$ and $93.3 \%$ in all-PET and PET-2 patients, respectively. A positive statistically significant correlation was found between VAHL and serology ranks in All-PET patients $\left(r_{s}=0.530, P v<0.001\right)$, and stronger correlation was found in PET-2 patients $\left(r_{s}=0.642, P v<0.001\right)$.

Conclusion: VAHL on $\left[{ }^{18}\right.$ F]FDG PET-CT of patients with hematologic malignancy may reflect GC B-cell proliferation and an effective humoral response elicited by BNT162b2 vaccine.

\section{Introduction}

Data on the immune response elicited by anti-SARS-CoV-2 vaccines is being accumulated in various patient cohorts [1-4]. Polack et al investigated the safety and efficacy of the BNT162b2 mRNA Covid-19 vaccine in healthy adults or those with chronic stable medical conditions, excluding patients treated with immunosuppressive therapies or diagnosed with immunocompromising conditions [1]. It was later observed that in immunocompromised patients, the elicited immune response to mRNA Covid-19 vaccine is reduced [2-3]. Boyarsky et al showed the poor humoral response elicited in a study of 346 solid organ transplant recipients [2]. Monin-Aldama et al showed that the post-BNT162b2 immune efficacy was strikingly low in solid cancer patients and even lower in patients with hematologic malignancy [3].

In a study of 261 patients with cancer, Thakkar et al showed the significantly lower seroconversion observed in patients with hematological malignancy after Covid-19 infection, particularly in patients 
exposed to anti-CD20 antibody containing therapy [5]. B-cell depletion by treatment with rituximab or obinutuzumab can also cause suppression of the immune response to vaccines [6-11]. These monoclonal antibodies act against the surface antigen protein CD20 expressed on B-lymphocyte during most of its developmental stages [12]. A study on rheumatic patients found that rituximab-treated patients had decreased responses to pneumococcal polysaccharide vaccine [7]. Another study found that Influenza vaccine responsiveness was poor in patients on rituximab [8]. In light of such results, several groups advise patients to consider the timing of Covid-19 vaccination relative to their anti-CD20 antibody therapy schedule [9-11].

Detection of regional lymphadenopathy after Covid-19 vaccines on various imaging modalities has been reported in case reports and small cohorts [13-25]. Recently, our group reported the incidence and time of appearance of BNT162b2 vaccine-associated hypermetabolic lymphadenopathy (VAHL) on $\left[{ }^{18} \mathrm{~F}\right] \mathrm{FDG}$ PET-CT [26].

While VAHL was reported after other vaccines in the past [27-29], no data exist on the correlation between VAHL and immunogenicity. In this study on patients with hematologic malignancy we aimed to explore the potential correlation between the phenomenon of reactive lymph nodes identified as hypermetabolic nodes on post-vaccination $\left[{ }^{18} \mathrm{~F}\right]$ FDG PET-CT and the humoral immunity of the patient reflected by post-vaccination serologic testing, and by comparing between patients treated recently with anti-CD20 antibody containing therapy and patients with similar disease not treated recently with B-cell depleting treatment.

\section{Methods}

\section{Patient Population.}

Since the introduction of the mass vaccination campaign against Covid-19 in late 2020 [30] and after receiving the consent of the institutional ethical committee, all patients over 16 years of age referred for whole-body $\left[{ }^{18} \mathrm{~F}\right] \mathrm{FDG}$ PET-CT in our department were interviewed regarding the dates of the vaccine doses they had and the site of injections [26]. Between December 27, 2020 and March 8, 2021, 150 vaccinated patients with hematologic malignancy that were clinically evaluated and treated at the hematology institute at Tel-Aviv Soursaky Medical Center were referred for $\left[{ }^{18}\right.$ F]FDG PET-CT in our department. Thirteen patients with malignant axillary and supraclavicular hypermetabolic lymphadenopathy (MHL) [26] were excluded. All other 137 vaccinated patients consist the study cohort (All-PET group), and include 102 lymphoma patients (86 Non-Hodgkin lymphoma; 16 Hodgkin lymphoma), 34 multiple myeloma patients, and one patient with chronic lymphocytic leukemia (CLL). Fifty one of the patients received the first vaccine dose only (PET-1 group) and 86 received both the first and booster vaccine doses (PET-2 group) before imaging.

Among the 102 lymphoma patients, 34 (33.3\%) were treated with anti-CD20 antibody containing regimen (30 with rituximab, 4 with obinutuzumab) during the 12-months prior to vaccination, median interval 
between last therapy and vaccination was 2.63 (IQR 0.70-5.98) months. The other 68 lymphoma patients included: 22 treatment-naïve patients, 22 who were treated with anti-CD20 antibody containing regimen > 12 month before vaccination (median interval 41.73, IQR 26.53-83.50 months), 19 received other systemic therapy (15 for Hodgkin lymphoma, 4 for T-cell lymphoma), and 5 received other therapies in the past.

A total of 54 patients (16 PET-1 patients and 38 PET-2 patients) underwent serologic testing following the booster vaccine dose, and were included in a subgroup analysis. Median time interval between the booster vaccine dose and serology testing was 17 (IQR 14.75-21) days. Table 1 and Table 2 summarize the characteristics of the total study cohort and the subgroup cohort, respectively.

\section{Imaging.}

$\left[{ }^{18}\right.$ F $]$ FDG PET-CT studies were performed on PET-CT scanners (GE Healthcare; DISCOVERY 690 and DISCOVERY Ml; 7 to 8 frames; frame time 1.5-3 minutes) according to our standard protocol [26]. Imaging data was reviewed and the presence or absence of "hot" axillary or supraclavicular lymph nodes (ASLN) ipsilateral to the vaccine injection site was recorded. Thus, scans were categorized as showing vaccineassociated hypermetabolic lymphadenopathy (VAHL) or no VAHL if no "hot" nodes were detected. All VAHL were graded on a 4 grade scale as described in our recent paper [26].

\section{Serology testing.}

Blood serum was collected 2-3 weeks after administration of the second BNT162b2 vaccine dose. Serum samples were analyzed by using Elecsys ${ }^{\circledR}$ Anti-SARS-CoV-2S assay on the cobas e 601 (Roche Diagnostics) for the quantitative detection of antibodies, predominantly IgG, aimed at the SARS-CoV-2 spike protein receptor binding domain. This assay has a measurement range of $0.40-250 \mathrm{U} / \mathrm{mL}$, with measured antibody concentration of $<0.80 \mathrm{U} / \mathrm{mL}$ considered as negative, and $\geq 0.80 \mathrm{U} / \mathrm{mL}$ as positive. When sample results exceeded the upper limit of the measuring range, antibodies concentration was quantitated by on-board dilution. For the purpose of the current study, antibodies concentration $\geq 0.80$ $\mathrm{U} / \mathrm{mL}$ but $<250 \mathrm{U} / \mathrm{mL}$ was graded as low titer, and antibodies concentration $\geq 250 \mathrm{U} / \mathrm{mL}$ was graded as high titer. To ensure that none of the patients had been recently exposed to SARS-CoV-2, an added test was run for the presence of antibodies to SARS-CoV-2 nucleocapsid by the Elecsys ${ }^{\circledR}$ Anti-SARS-CoV-2 assay using the cobas e 601 (Roche Diagnostics).

\section{Statistical analysis.}

Categorical variables were reported as frequency and percentage. Continuous variables were evaluated for normal distribution and reported as median and interquartile range (IQR). Chi-square test and Fisher's exact test were applied to compare proportions between groups. Independent samples Kruskal-Wallis test and Mann-Whitney test were used to compare continuous variables. Spearman's rank-order correlation was run to determine the relationship between ordinal variables. All statistical tests were 
performed using SPSS Statistics Version 27 (IBM, Armonk, NY, USA), were two-sided and Pv $<0.05$ was considered statistically significant.

\section{Results}

Vaccine-associated hypermetabolic lymphadenopathy in patients with hematologic malignancy

The incidences of VAHL among vaccinated patients with hematologic malignancy were $31.4 \%, 25.5 \%$ and $34.9 \%$ in All-PET, PET-1 and PET-2 groups, respectively. Table 3 details the incidences of VAHL also for lymphoma and myeloma patients separately.

Comparing lymphoma and myeloma patients, myeloma patients had non-significant higher rates of VAHL: $35.3 \%$ versus $30.4 \%$ in All-PET group, $27.3 \%$ versus $25.6 \%$ in PET-1 group and $39.1 \%$ versus $33.3 \%$ in PET-2 group (Fig. 1, upper row).

Among the 102 vaccinated lymphoma patients, 34 (33.3\%) were treated with anti-CD20 antibodies during the year before vaccination (median time since last therapy was 2.63 months). The incidence of VAHL in patients recently treated with anti-CD20 antibody containing regimen was significantly lower compared to other lymphoma patients in All-PET, PET-1 and PET-2 patients (Fig. 1, lower row). Only 3 of 34 (8.8\%) lymphoma patients recently treated with anti-CD20 antibody containing therapy showed VAHL on their $\left[{ }^{18}\right.$ F]FDG PET-CT study, compared with $41.2 \%$ lymphoma patients not treated recently with anti-CD20 antibodies. Of note, 2 of the 3 VAHL-positive patients treated with anti-CD20 antibody containing regimen during the last year received the last treatment 9.8 and 11.8 months before vaccination.

The relationship between vaccine-associated hypermetabolic lymphadenopathy and post-vaccination antibody secretion

In 54 patients, post-vaccination $\left[{ }^{18}\right.$ F]FDG PET-CT studies and serologic analysis were performed. Sixteen of them had their imaging study after the first vaccine dose, and the median interval between imaging and serology analysis was 29.5 (IQR 21-34.5) days. Thirty eight of them had their imaging study after the booster vaccine dose, and the median interval between imaging and serology analysis was 0.5 (IQR - 12 - 8) days.

In 20 patients the serology result was negative (all had anti-spike antibodies concentration $\leq 0.40 \mathrm{U} / \mathrm{mL}$ ), 16 patients had a low anti-spike titers (median antibody concentration 7.6, IQR 4.8-110.9 U/mL) and 18 patients had high anti-spike titers (median antibody concentration 688.4, IQR 426.2-1416 U/mL). As presented on Table 4, the three groups did not differ significantly in terms of age, gender and disease composition. The incidence of VAHL differed significantly between the three groups: only 2 of $20(10 \%)$ patients with negative serology showed VAHL on imaging, while $31.3 \%$ of those with low anti-spike titers and $72.2 \%$ of those with high anti-spike titers had VAHL on their PET study. Figure 2 (upper row) illustrates that VAHL grades were different as well between the groups, and that the differences were more prominent in the patients having their $\left[{ }^{18}\right.$ F $]$ FDG PET-CT after the booster vaccine dose. 
Calculation of the predictive values of $\left[{ }^{18} \mathrm{~F}\right] \mathrm{FDG}$ PET-CT in predicting the humoral immunity and potential to have a positive post-vaccination serology is illustrated in Fig. 2, lower row. The positive predictive values (PPV) were high: $90 \%$ (95\% Cl, 76.9\%-100\%) for All-PET patient and 93.3\% (95\% Cl, 81.9\%-100\%) for PET-2 patients. Negative predicting values were low: $52.9 \%(95 \% \mathrm{Cl}, 36.2 \%-69.7 \%)$ for All-PET patient and $65.2 \%(95 \% \mathrm{Cl}, 45.8 \%-84.7 \%)$ for PET-2 patients.

A Spearman's rank-order correlation was run to determine the relationship between serology-based and VAHL-based ranks. In the total 54 patients, there was a positive correlation between the variables, which was statistically significant $\left(r_{s}=0.530, P v<0.001\right)$. No statistically significant correlation was observed in the population of 16 PET-1 patients $\left(r_{s}=0.279, P v=0.295\right)$, but a stronger correlation was observed in the 38 PET-2 patients $\left(r_{s}=0.642, \mathrm{PV}<0.001\right)$. Similar results were observed in subgroups of patients with lymphoma and myeloma separately (Fig. 3).

\section{Discussion}

The immune responses elicited by vaccines [31] is studied in depth lately, particularly since the introduction of the novel anti-SARS-CoV-2 mRNA vaccines [32-34]. After intramuscular administration of the vaccine, antigen-presenting cells (APCs) loaded with antigen migrate to regional lymph nodes, where they present peptide antigens and elicit two main responses: cellular response, with the formation of cytotoxic $T$ lymphocytes capable of directly killing infected cells, and humoral response, which depends on B-cells proliferation in the germinal center (GC) of the lymph node and the formation of matured Bcells as antibody secreting plasma cells and memory B-cells [32].

Recent studies have highlighted the prominent GC response elicited by mRNA vaccines in the lymph nodes reactive to the vaccine, and the pivotal role the GC response plays in the humoral response [3334]. Lederer et al showed the stronger GC response elicited by SARS-CoV-2 mRNA vaccine compared with recombinant protein formulated vaccine [33]. A recent study by Ellebedy et al, that also included fine needle aspirates of draining axillary lymph nodes, emphasizes how the robust and persistent GC B-cell response is essential for durable humoral immunity [34].

In this study, we aimed to investigate the correlation between VAHL and the humoral response elicited by Covid-19 vaccine in patients with hematologic malignancy. $\left[{ }^{18} \mathrm{~F}\right] \mathrm{FDG}$-positivity in ASLN ipsilateral to the vaccine injection site reflects hypermetabolism and proliferation of cells within the involved lymph nodes. A group of patients that were recently treated with anti-CD20 antibodies were our model for B-cell depletion. The significant lower rates of VAHL observed in this patient group enforces the possibility that VAHL is a reflection of GC B-cell proliferation as part of the early stage of the humoral response to vaccination. This observation motivated us to further explore the correlation between VAHL and the later stage of the humoral response: antibody secretion as assessed by serologic testing.

We identified in this study a subgroup of 54 patients with hematologic malignancy that had $\left[{ }^{18} \mathrm{~F}\right] \mathrm{FDG}$ PET-CT study after vaccination and also had post-vaccination serologic testing. The findings of VAHL on 
imaging was found to be concordant with serology results: VAHL incidence was the highest among patients with high anti-spike titers, and the finding of VAHL showed an overall PPV of $90 \%$ in predicting post-vaccination serology positivity. Statistically significant positive correlation was found between VAHL-based and serology-based ranks. All of the above results were more prominent in patients having a $\left[{ }^{18}\right.$ F]FDG PET-CT study after the booster dose of the vaccine. This positive correlation indicates that the detection VAHL suggests an effective humoral response and a higher likelihood that antibodies may be produced. However, one should not consider the absence of VAHL on PET as indicative of impaired humoral response.

\section{Conclusions}

In patients with hematologic malignancy, VAHL detected on [ $\left.{ }^{18} \mathrm{~F}\right] \mathrm{FDG}$ PET-CT positively correlates with antibody-mediated immune response to Covid-19 vaccine and is barely observed in patients exposed to anti-CD20 antibody containing therapy during the last year prior vaccination.

\section{Abbreviations}

HLN: Hypermetabolic lymphadenopathy

VAHL: Vaccine-associated hypermetabolic lymphadenopathy

MHL: Malignant hypermetabolic lymphadenopathy

ASLN: Axillary or supraclavicular lymph nodes

$\left[{ }^{18} \mathrm{~F}\right] \mathrm{FDG}:{ }^{18} \mathrm{~F}$-fluorodeoxyglucose

PET-CT: Positron emission tomography - computed tomography

SUV: Standardized uptake value

MIP: Maximal intensity projection

mRNA: Messenger ribonucleic acid

SARS-CoV-2: Severe acute respiratory syndrome coronavirus 2

Covid-19: Coronavirus disease 2019

CLL: Chronic lymphocytic leukemia

CD20: Cluster of differentiation 20

APC: Antigen presenting cell 
GC: Germinal center

Pv: P-Value

IQR: Interquartile range

Cl: Confidence interval

$r_{s}$ : Spearman's rank correlation coefficient

\section{Declarations}

\section{Declarations/ Competing interests}

YH reports honoraria from AbbVie, Janssen, Astra-Zeneca and Roche outside the submitted work. All other authors have no relevant financial or non-financial interests to disclose and have no conflicts of interest to declare that are relevant to the content of this article.

\section{Acknowledgements}

None.

\section{Funding}

No funding was received.

\section{Availability of data and materials}

The datasets used and/or analyzed during the current study are available from the corresponding author on reasonable request.

\section{Ethics approval and consent to participate}

All procedures performed in studies involving human participants were in accordance with the ethical standards of the institutional and/or national research committee and with the 1964 Helsinki Declaration and its later amendments or comparable ethical standards. All included imaging data was collected as part of a retrospective study protocol approved by the local institutional ethics committee which waived written informed consent (Reference ID 0056-21-TLV). All included patient that had post-vaccination serology testing provided informed consent and took part in a prospective study approved by the institutional review board (Reference ID 1068-20-TLV) and registered in ClinicalTrials.gov (number NCT04746092, registered February 9, 2021).

\section{Consent for publication}

Not applicable. 


\section{References}

1. Polack FP, Thomas SJ, Kitchin N, Absalon J, Gurtman A, Lockhart S, Perez JL, Pérez Marc G, Moreira ED, Zerbini C, Bailey R. Safety and efficacy of the BNT162b2 mRNA Covid-19 vaccine. New England Journal of Medicine. 2020 Dec 31;383(27):2603-15. https://doi.org/10.1056/NEJMoa2034577.

2. Boyarsky BJ, Werbel WA, Avery RK, Tobian AA, Massie AB, Segev DL, Garonzik-Wang JM. Immunogenicity of a single dose of SARS-CoV-2 messenger RNA vaccine in solid organ transplant recipients. JAMA. 2021 Mar 15. https://doi.org/10.1001/jama.2021.4385

3. Monin-Aldama L, Laing AG, Munoz-Ruiz M, McKenzie DR, del Barrio ID, Alaguthurai T, Domingo-Vila C, Hayday TS, Graham C, Seow J, Abdul-Jawad S. Interim results of the safety and immune-efficacy of 1 versus 2 doses of COVID-19 vaccine BNT162b2 for cancer patients in the context of the UK vaccine priority guidelines. medRxiv. 2021 Jan 1. https://doi.org/10.1101/2021.03.17.21253131

4. Sahin U, Muik A, Derhovanessian E, Vogler I, Kranz LM, Vormehr M, Baum A, Pascal K, Quandt J, Maurus D, Brachtendorf S. COVID-19 vaccine BNT162b1 elicits human antibody and TH $1 \mathrm{~T}$ cell responses. Nature. 2020 Oct;586(7830):594-9. https:// doi.org/10.1038/s41586-020-2814-7

5. Thakkar A, Pradhan K, Jindal S, Cui Z, Rockwell B, Shah AP, Packer S, Sica RA, Sparano J, Goldstein DY, Verma A. Patterns of seroconversion for SARS-CoV-2 IgG in patients with malignant disease and association with anticancer therapy. Nature Cancer. 2021 Mar 22:1-8.

https://doi.org/10.1038/s43018-021-00191-y

6. Subesinghe S, Bechman K, Rutherford Al, Goldblatt D, Galloway JB. A systematic review and metaanalysis of antirheumatic drugs and vaccine immunogenicity in rheumatoid arthritis. The Journal of rheumatology. 2018 Jun 1;45(6):733-44. https://doi.org/10.3899/jrheum.170710

7. Bingham III CO, Looney RJ, Deodhar A, Halsey N, Greenwald M, Codding C, Trzaskoma B, Martin F, Agarwal S, Kelman A. Immunization responses in rheumatoid arthritis patients treated with rituximab: results from a controlled clinical trial. Arthritis \& Rheumatism: Official Journal of the American College of Rheumatology. 2010 Jan;62(1):64-74. https://doi.org/10.1002/art.25034

8. Eisenberg RA, Jawad AF, Boyer J, Maurer K, McDonald K, Prak ET, Sullivan KE. Rituximab-treated patients have a poor response to influenza vaccination. Journal of clinical immunology. $2013 \mathrm{Feb}$ 1;33(2):388-96. https://doi.org/10.1007/s10875-012-9813-x

9. Sonani B, Aslam F, Goyal A, Patel J, Bansal P. COVID-19 vaccination in immunocompromised patients. Clinical Rheumatology. 2020 Nov 25:1-2. https://doi.org/10.1007/s10067-020-05547-w

10. Furer V, Rondaan C, Agmon-Levin N, Van Assen S, Bijl M, Kapetanovic MC, De Thurah A, MuellerLadner U, Paran D, Schreiber K, Warnatz K. Point of view on the vaccination against COVID-19 in patients with autoimmune inflammatory rheumatic diseases. RMD open. 2021 Feb 1;7(1):e001594. http://dx.doi.org/10.1136/rmdopen-2021-001594

11. American College of Rheumatology. COVID-19 Vaccine Clinical Guidance Summary for Patients with Rheumatic and Musculoskeletal Diseases. https://www.rheumatology.org/Portals/0/Files/COVID-19Vaccine-Clinical-Guidance-Rheumatic-Diseases-Summary.pdf. Accessed April 4, 2021. 
12. Pierpont TM, Limper CB, Richards KL. Past, present, and future of rituximab-the world's first oncology monoclonal antibody therapy. Frontiers in oncology. 2018 Jun 4;8:163. https://doi.org/10.3389/fonc.2018.00163

13. Becker AS, Perez-Johnston R, Chikarmane SA, Chen MM, El Homsi M, Feigin KN, Gallagher KM, Hanna EY, Hicks M, llica AT, Mayer EL. Multidisciplinary Recommendations Regarding Post-Vaccine Adenopathy and Radiologic Imaging: Radiology Scientific Expert Panel. Radiology. 2021 Feb 24:210436. https://doi.org/10.1148/radiol.2021210436.

14. Mortazavi S. Coronavirus Disease (COVID-19) Vaccination Associated Axillary Adenopathy: Imaging Findings and Follow-Up Recommendations in 23 Women. American Journal of Roentgenology. 2021 Feb 24. https://doi.org/10.2214/AJR.21.25651.

15. Edmonds CE, Zuckerman SP, Conant EF. Management of unilateral axillary lymphadenopathy detected on breast MRI in the era of coronavirus disease (COVID-19) vaccination. American Journal of Roentgenology. 2021 Feb 5. https://doi.org/10.2214/AJR.21.25604.

16. Lehman CD, Lamb LR, D'Alessandro HA. Mitigating the Impact of Coronavirus Disease (COVID-19) Vaccinations on Patients Undergoing Breast Imaging Examinations: A Pragmatic Approach. American Journal of Roentgenology. 2021 Feb 22. https://doi.org/10.2214/AJR.21.25688.

17. Özütemiz C, Krystosek LA, Church AL, Chauhan A, Ellermann JM, Domingo-Musibay E, Steinberger D. Lymphadenopathy in COVID-19 Vaccine Recipients: Diagnostic Dilemma in Oncology Patients. Radiology. 2021 Feb 24:210275. https://doi.org/10.1148/radiol.2021210275.

18. Mehta N, Sales RM, Babagbemi K, Levy AD, McGrath AL, Drotman M, Dodelzon K. Unilateral axillary Adenopathy in the setting of COVID-19 vaccine. Clinical imaging. 2021 Jul 1;75:12-5. https://doi.org/10.1016/j.clinimag.2021.01.016.

19. Ahn RW, Mootz AR, Brewington CC, Abbara S. Axillary Lymphadenopathy After mRNA COVID-19 Vaccination. Radiology: Cardiothoracic Imaging. 2021 Feb 3;3(1):e210008. https://doi.org/10.1148/ryct.2021210008.

20. Eifer M, Eshet Y. Imaging of COVID-19 Vaccination at FDG PET/CT. Radiology 2021. https://doi.org/10.1148/radiol.2020210030.

21. Hanneman K, Iwanochko RM, Thavendiranathan P. Evolution of Lymphadenopathy at PET/MRI after COVID-19 Vaccination. Radiology. 2021 Feb 24:210386. https://doi.org/10.1148/radiol.2021210386.

22. Nawwar AA, Searle J, Singh R, Lyburn ID. Oxford-AstraZeneca COVID-19 vaccination induced lymphadenopathy on [18F] Choline PET/CT-not only an FDG finding. European Journal of Nuclear Medicine and Molecular Imaging. 2021 Mar 4:1-2. https://doi.org/10.1007/s00259-021-05279-2.

23. Nawwar AA, Searle J, Hagan I, Lyburn ID. COVID-19 vaccination induced axillary nodal uptake on [18F] FDG PET/CT. European journal of nuclear medicine and molecular imaging. 2021 Feb 26:1-2. https://doi.org/10.1007/s00259-021-05274-7.

24. Avner M, Orevi M, Caplan N, Popovtzer A, Lotem M, Cohen JE. COVID-19 vaccine as a cause for unilateral lymphadenopathy detected by $18 \mathrm{~F}-\mathrm{FDG}$ PET/CT in a patient affected by melanoma. 
European Journal of Nuclear Medicine and Molecular Imaging. 2021 Mar 6:1-2. https://doi.org/10.1007/s00259-021-05278-3.

25. Moghimi S, Wilson D, Martineau P. FDG PET Findings Post-COVID Vaccinations: Signs of the Times?. Clinical Nuclear Medicine. 2021 Mar 4. https://doi.org/10.1097/RLU.0000000000003636

26. Cohen D, Krauthammer SH, Wolf I, Even-Sapir E. Hypermetabolic lymphadenopathy following administration of BNT162b2 mRNA Covid-19 vaccine: incidence assessed by [18 F] FDG PET-CT and relevance to study interpretation. European Journal of Nuclear Medicine and Molecular Imaging. 2021 Mar 27:1-0. https://doi.org/10.1007/s00259-021-05314-2

27. Panagiotidis E, Exarhos D, Housianakou I, Bournazos A, Datseris I. FDG uptake in axillary lymph nodes after vaccination against pandemic (H1N1). European radiology. 2010 May;20(5):1251-3. https://doi.org/10.1007/s00330-010-1719-5.

28. Burger IA, Husmann L, Hany TF, Schmid DT, Schaefer NG. Incidence and intensity of F-18 FDG uptake after vaccination with H1N1 vaccine. Clinical nuclear medicine. 2011 Oct 1;36(10):848-53. https://doi.org/10.1097/RLU.0b013e3182177322.

29. Coates EE, Costner PJ, Nason MC, Herrin DM, Conant S, Herscovitch P, Sarwar UN, Holman L, Mitchell J, Yamshchikov G, Koup RA. Lymph node activation by PET/CT following vaccination with licensed vaccines for human papillomaviruses. Clinical Nuclear Medicine. 2017 May 1;42(5):329-34. https://doi.org/10.1097/RLU.0000000000001603.

30. Dagan N, Barda N, Kepten E, Miron O, Perchik S, Katz MA, Hernán MA, Lipsitch M, Reis B, Balicer RD. BNT162b2 mRNA Covid-19 vaccine in a nationwide mass vaccination setting. New England Journal of Medicine. 2021 Feb 24. https://doi.org/10.1056/NEJMoa2101765.

31. Pal I, Ramsey JD. The role of the lymphatic system in vaccine trafficking and immune response. Advanced drug delivery reviews. 2011 Sep 10;63(10-11):909-22. https://doi.org/10.1016/j.addr.2011.05.018

32. Bettini E, Locci M. SARS-CoV-2 mRNA Vaccines: Immunological mechanism and beyond. Vaccines. 2021 Feb;9(2):147. https://doi.org/10.3390/vaccines9020147

33. Lederer K, Castaño D, Atria DG, Oguin III TH, Wang S, Manzoni TB, Muramatsu H, Hogan MJ, Amanat $F$, Cherubin P, Lundgreen KA. SARS-CoV-2 mRNA vaccines foster potent antigen-specific germinal center responses associated with neutralizing antibody generation. Immunity. 2020 Dec 15;53(6):1281-95. https://doi.org/10.1016/j.immuni.2020.11.009

34. Ellebedy A, Turner J, O'Halloran J, et al. SARS-CoV-2 mRNA vaccines induce a robust germinal centre reaction in humans. Research Square; 2021. https://doi.org/10.21203/rs.3.rs-310773/v1

\section{Tables}


Table 1

Study population characteristics

\begin{tabular}{|llll|}
\hline & $\begin{array}{l}\text { All patients with hematologic } \\
\text { malignancy }\end{array}$ & $\begin{array}{l}\text { Lymphoma } \\
\text { patients }\end{array}$ & Myeloma patients \\
\hline Age (years) & $(\mathbf{n = 1 3 7 )}$ & $(\mathbf{n}=102)$ & $(\mathbf{n}=34)$ \\
\hline Male & $68.5(58.4-76.1)$ & $68.4(58.4-76.8)$ & $68.3(56.1-74.9)$ \\
\hline Vac-1 patients & $75(54.7 \%)$ & $52(51.0 \%)$ & $22(64.7 \%)$ \\
$\begin{array}{l}\text { Days from Vac-1 to PET- } \\
\text { CT }\end{array}$ & $51(37.2 \%)$ & $39(38.2 \%)$ & $11(32.4 \%)$ \\
\hline Vac-2 patients & $10(6-15)$ & $10(5-15)$ & $12(8-16)$ \\
$\begin{array}{l}\text { Days from Vac-2 to PET- } \\
\text { CT }\end{array}$ & $19(10-27)$ & $63(61.8 \%)$ & $23(67.6 \%)$ \\
\hline $\begin{array}{l}\text { Staging } \\
\text { Monitor response to } \\
\text { therapy }\end{array}$ & $26(19.0 \%)$ & $17(10-27)$ & $22(11-30)$ \\
Recurrence & $59(43.1 \%)$ & $20(19.6 \%)$ & $6(17.6 \%)$ \\
Follow-up with NED & $30(21.9 \%)$ & $38(37.3 \%)$ & $20(58.8 \%)$ \\
\hline
\end{tabular}

Categorical variables are reported as frequency and percentage; Continuous variables are reported as median and IQR. Vac-1, first vaccine dose; Vac-2, booster vaccine dose; NED, no evidence of disease 
Table 2

Characteristics of the subgroup of patients with post-vaccination serology testing

\begin{tabular}{|c|c|c|c|}
\hline & $\begin{array}{l}\text { All patients with hematologic } \\
\text { malignancy }\end{array}$ & $\begin{array}{l}\text { Lymphoma } \\
\text { patients }\end{array}$ & $\begin{array}{l}\text { Myeloma } \\
\text { patients }\end{array}$ \\
\hline & $(n=54)$ & $(n=33)$ & $(n=20)$ \\
\hline Age (years) & $68.8(61.2-76.8)$ & $\begin{array}{l}66.6(52.3- \\
76.4)\end{array}$ & $\begin{array}{l}70.7(63.5- \\
77.0)\end{array}$ \\
\hline Male & $32(59.3 \%)$ & $19(57.6 \%)$ & $12(60.0 \%)$ \\
\hline Vac-1 patients & $16(29.6 \%)$ & $8(24.2 \%)$ & $7(35.0 \%)$ \\
\hline Days from Vac- 1 to PET-CT & $11(7-15.75)$ & $10(4-14.75)$ & $14(10-17)$ \\
\hline $\begin{array}{l}\text { Days from PET-CT to } \\
\text { Serology }\end{array}$ & $29.5(21-34.5)$ & $32(21-37.25)$ & $26(21-31)$ \\
\hline Vac-2 patients & $38(70.4 \%)$ & $25(75.8 \%)$ & $13(65.0 \%)$ \\
\hline Days from Vac-2 to PET-CT & $17(10-31)$ & $14(9-28)$ & $25(11.5-32.5)$ \\
\hline $\begin{array}{l}\text { Days from PET-CT to } \\
\text { Serology }\end{array}$ & $0.5(-12-8)$ & $1(-9.5-9.5)$ & $-4(-13.5-5)$ \\
\hline $\begin{array}{l}\text { Days from Vac-2 to } \\
\text { serology }\end{array}$ & $17(14.75-21)$ & $17(15-21.5)$ & $\begin{array}{l}16.5(14.25- \\
21)\end{array}$ \\
\hline Staging & $7(13.0 \%)$ & $3(9.1 \%)$ & $4(20.0 \%)$ \\
\hline \multirow{2}{*}{$\begin{array}{l}\text { Monitor response to } \\
\text { therapy }\end{array}$} & $35(64.8 \%)$ & $21(63.6 \%)$ & $13(65.0 \%)$ \\
\hline & $3(5.6 \%)$ & $2(6.1 \%)$ & $1(5.0 \%)$ \\
\hline Follow-up with NED & $9(16.7 \%)$ & $7(21.2 \%)$ & $2(10.0 \%)$ \\
\hline
\end{tabular}

Categorical variables are reported as frequency and percentage; Continuous variables are reported as median and IQR. Vac-1, first vaccine dose; Vac-2, booster vaccine dose; NED, no evidence of disease 
Table 3

VAHL incidences in the study groups

\begin{tabular}{|c|c|c|c|c|}
\hline \multirow[t]{6}{*}{$\begin{array}{l}\text { All-PET group }(\mathrm{n} \\
=137)\end{array}$} & & $\begin{array}{l}\text { All patients with hematologic } \\
\text { malignancy }\end{array}$ & $\begin{array}{l}\text { Lymphoma } \\
\text { patients }\end{array}$ & $\begin{array}{l}\text { Myeloma } \\
\text { patients }\end{array}$ \\
\hline & & $(n=137)$ & $(n=102)$ & $(n=34)$ \\
\hline & no VAHL & 94 (68.6\%) & 71 (69.6\%) & $22(64.7 \%)$ \\
\hline & VAHL & 43 (31.4\%) & 31 (30.4\%) & $12(35.3 \%)$ \\
\hline & $\begin{array}{l}\text { grade 1-2 } \\
\text { VAHL }\end{array}$ & 31 (22.6\%) & $21(20.6 \%)$ & 10 (29.4\%) \\
\hline & $\begin{array}{l}\text { grade } 3-4 \\
\text { VAHL }\end{array}$ & 12 (8.8\%) & $10(9.8 \%)$ & 2 (5.9\%) \\
\hline \multirow{6}{*}{$\begin{array}{l}\text { PET-1 group } \\
(n=51)\end{array}$} & & $\begin{array}{l}\text { All patients with hematologic } \\
\text { malignancy }\end{array}$ & $\begin{array}{l}\text { Lymphoma } \\
\text { patients }\end{array}$ & $\begin{array}{l}\text { Myeloma } \\
\text { patients }\end{array}$ \\
\hline & & $(n=51)$ & $(n=39)$ & $(n=11)$ \\
\hline & no VAHL & 38 (74.5\%) & 29 (74.4\%) & 8 (72.7\%) \\
\hline & VAHL & 13 (25.5\%) & $10(25.6 \%)$ & $3(27.3 \%)$ \\
\hline & $\begin{array}{l}\text { grade } 1-2 \\
\text { VAHL }\end{array}$ & $11(21.6 \%)$ & $9(23.1 \%)$ & $2(18.2 \%)$ \\
\hline & $\begin{array}{l}\text { grade } 3-4 \\
\text { VAHL }\end{array}$ & 2 (3.9\%) & $1(2.6 \%)$ & $1(9.1 \%)$ \\
\hline \multirow{6}{*}{$\begin{array}{l}\text { PET-2 group } \\
(n=86)\end{array}$} & & $\begin{array}{l}\text { All patients with hematologic } \\
\text { malignancy }\end{array}$ & $\begin{array}{l}\text { Lymphoma } \\
\text { patients }\end{array}$ & $\begin{array}{l}\text { Myeloma } \\
\text { patients }\end{array}$ \\
\hline & & $(n=86)$ & $(n=63)$ & $(n=23)$ \\
\hline & no VAHL & $56(65.1 \%)$ & $42(66.7 \%)$ & $14(60.9 \%)$ \\
\hline & VAHL & 30 (34.9\%) & $21(33.3 \%)$ & $9(39.1 \%)$ \\
\hline & $\begin{array}{l}\text { grade } 1-2 \\
\text { VAHL }\end{array}$ & 20 (23.3\%) & 12 (19.0\%) & $8(34.8 \%)$ \\
\hline & $\begin{array}{l}\text { grade } 3-4 \\
\text { VAHL }\end{array}$ & 10 (11.6\%) & 9 (14.3\%) & $1(4.3 \%)$ \\
\hline
\end{tabular}

Categorical variables are reported as frequency and percentage. All-PET group refers to all patients with hematologic malignancy that underwent $\left[{ }^{18} \mathrm{~F}\right] \mathrm{FDG}$ PET-CT after BNT162b2 administration. PET-1 group includes those received the first vaccine dose only before imaging, and PET-2 group to those received the booster dose as well 
Table 4

Patients characteristics in different serology-based groups

\begin{tabular}{|lllll|}
\hline & negative serology & low titer & high titer & Pv \\
\hline Age (years) & $(\mathbf{n = 2 0 )}$ & $\mathbf{( n = 1 6 )}$ & $\mathbf{( n = 1 8 )}$ & \\
\hline Male & $\begin{array}{l}73.21(66.13- \\
77.98)\end{array}$ & $\begin{array}{l}65.28(54.71- \\
75.45)\end{array}$ & $\begin{array}{l}66.00(48.74- \\
76.51)\end{array}$ & 0.220 \\
\hline Lymphoma & $13(65 \%)$ & $9(56.3 \%)$ & $10(55.6 \%)$ & 0.804 \\
\hline Myeloma & $16(80 \%)$ & $7(43.8 \%)$ & $10(55.6 \%)$ & \\
\hline CLL & $4(20 \%)$ & $8(50 \%)$ & $8(44.4 \%)$ & 0.084 \\
\hline VAHL on PET-CT & $2(10 \%)$ & $1(6.3 \%)$ & $0(0 \%)$ & \\
\hline $\begin{array}{l}\text { VAHL on PET-CT after } \\
\text { Vac-1 }\end{array}$ & $1 / 4(25 \%)$ & $5(31.3 \%)$ & $13(72.2 \%)$ & $<0.001$ \\
\hline $\begin{array}{l}\text { VAHL on PET-CT after } \\
\text { Vac-2 }\end{array}$ & $1 / 16(6.3 \%)$ & $4 / 10(40 \%)$ & $10 / 12(83.3 \%)$ & $<0.001$ \\
\hline
\end{tabular}

Categorical variables are reported as frequency and percentage; Continuous variables are reported as median and IQR. Vac-1, first vaccine dose; Vac-2, booster vaccine dose

a. a statistically significant difference found between negative serology and low titer groups;

b: a statistically significant difference found between negative serology and high titer groups;

c. a statistically significant difference found between low titer and high titer groups.

\section{Figures}


All-PET group

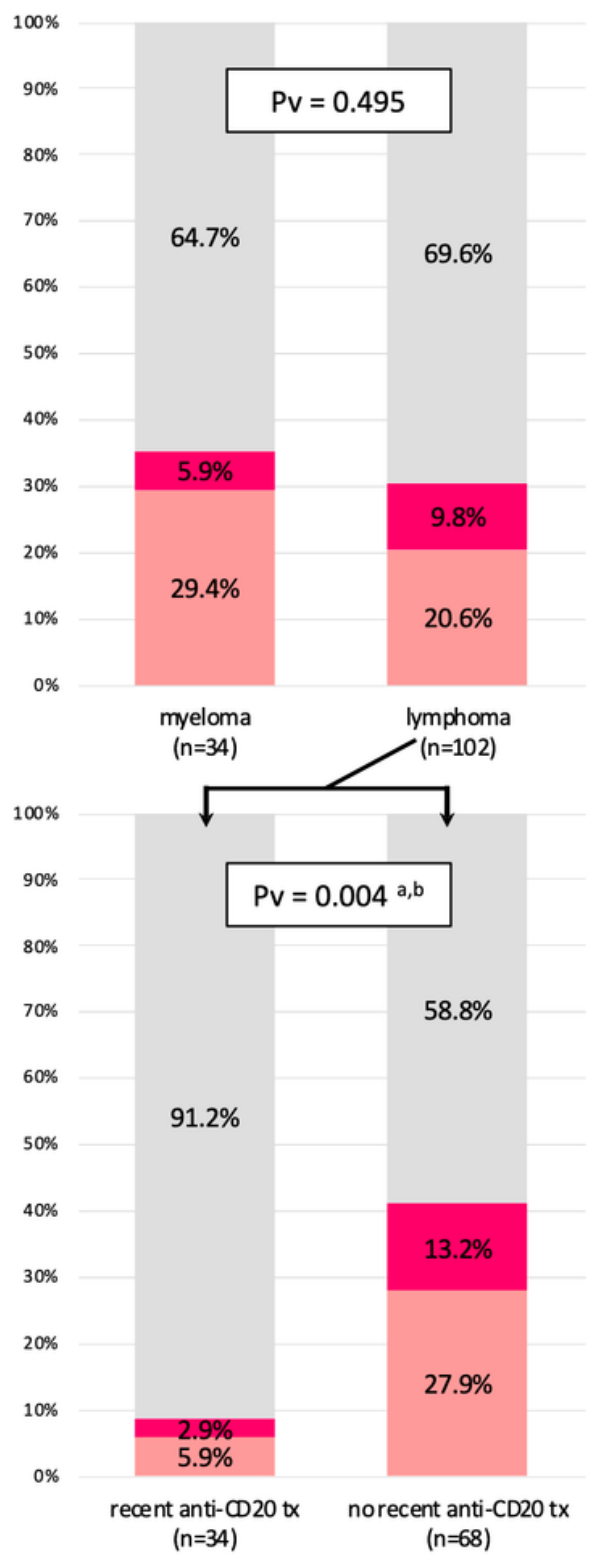

PET-1 group

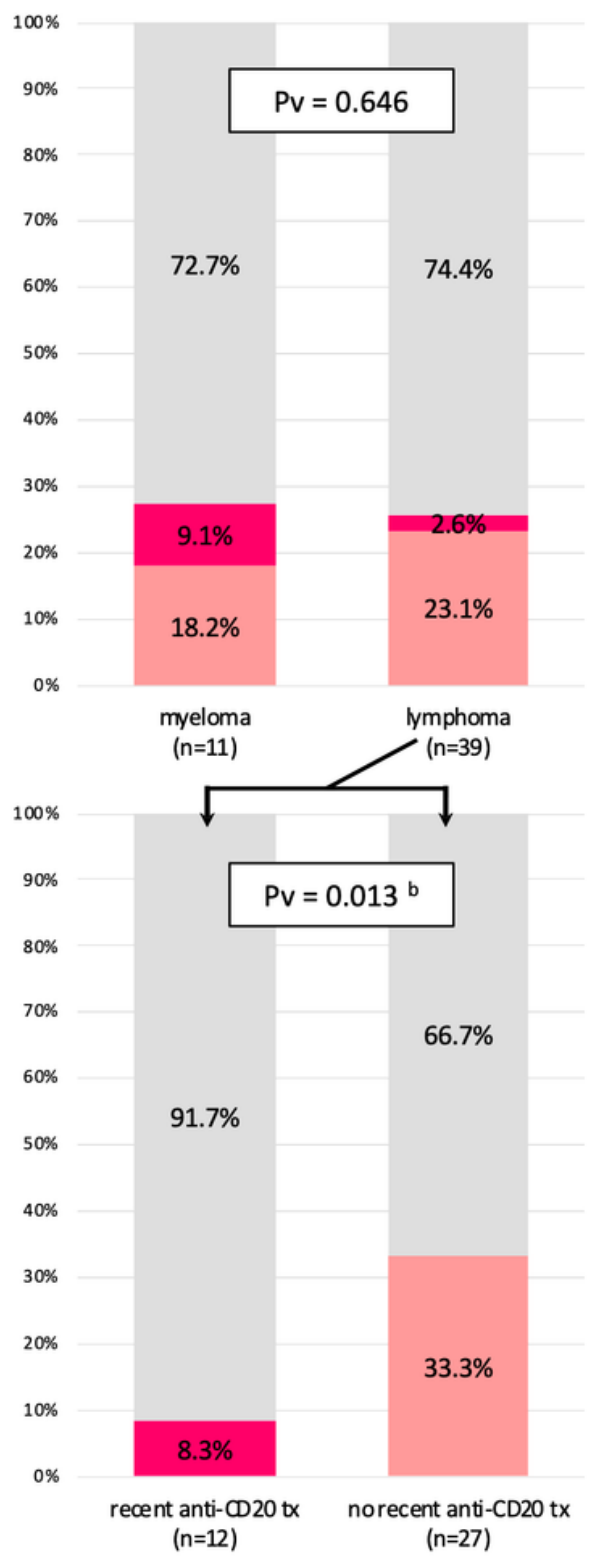

arade 1-2 VAHL a grade 3-4 VAHL no VAHL
PET-2 group

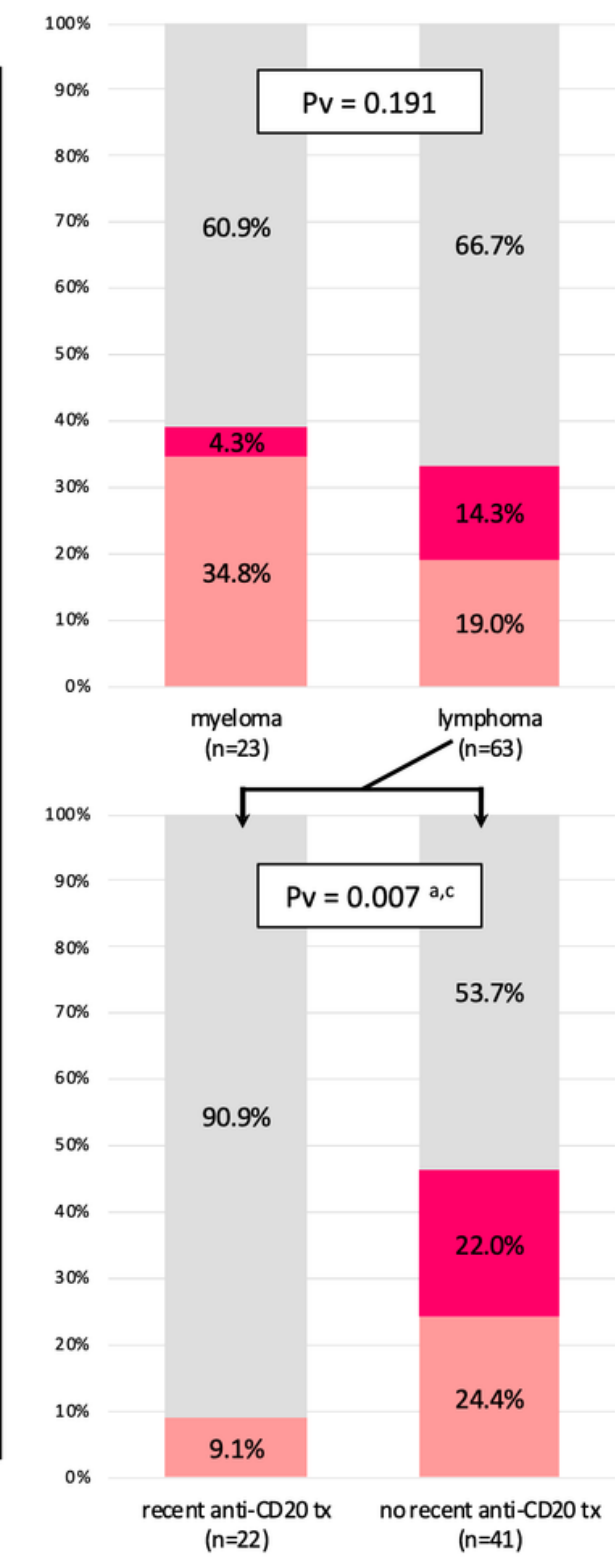

\section{Figure 1}

Vaccine-associated hypermetabolic lymphadenopathy rates in myeloma and lymphoma patients. Note on the lower row the significant lower VAHL rates in lymphoma patients treated recently with anti-CD20 antibody containing therapy. All-PET group refers to all patients with hematologic malignancy that underwent [18F]FDG PET-CT after BNT162b2 administration. PET-1 group includes those received the first vaccine dose only before imaging, and PET-2 group to those received the booster dose as well a: a statistically significant difference of no VAHL rates was found between compared groups; $b$ : a statistically significant difference of grade 1-2 VAHL rates was found between compared groups; c: a statistically significant difference of grade 3-4 VAHL rates was found between compared groups; 
All-PET patients
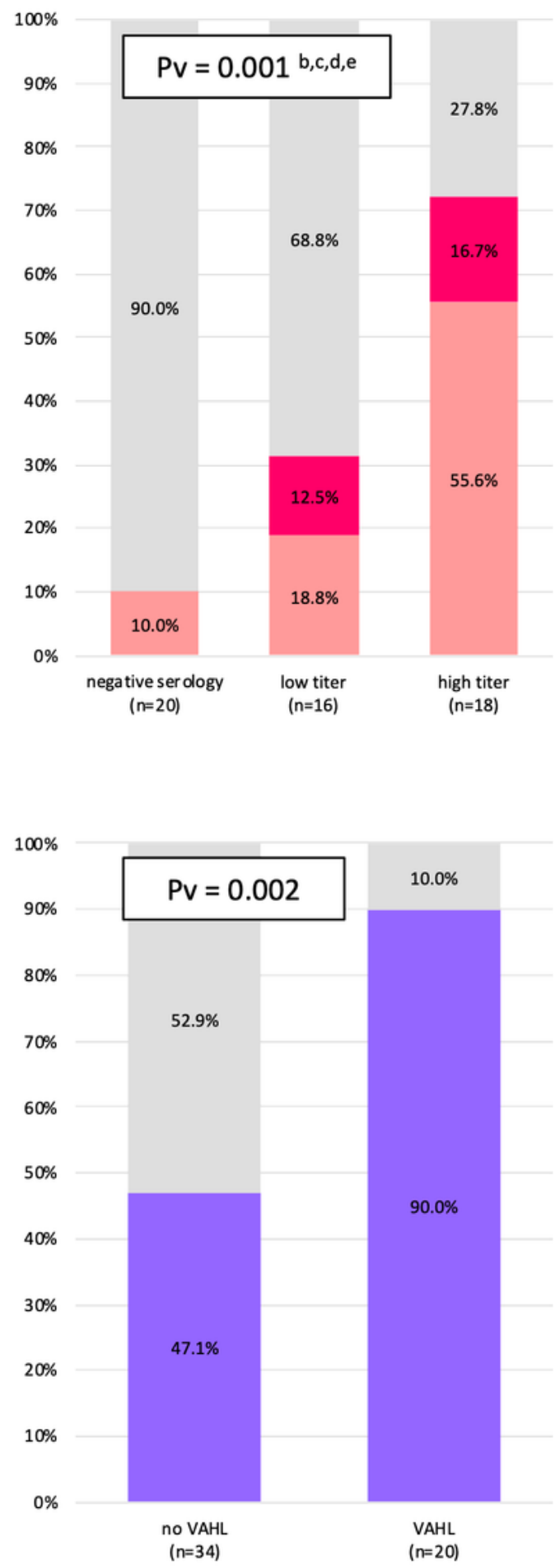

PET-2 patients
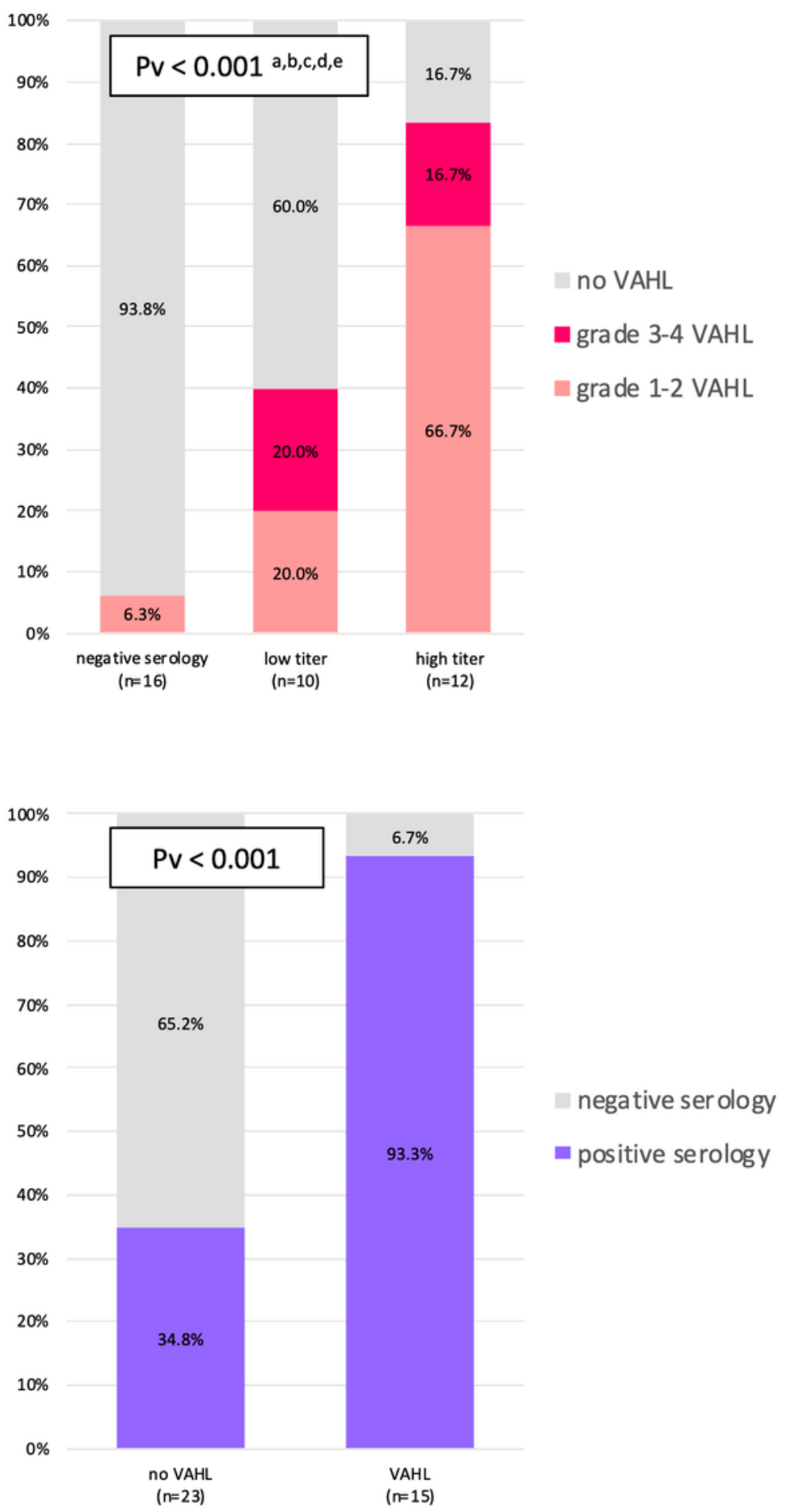

\section{Figure 2}

Upper row: Vaccine-associated hypermetabolic lymphadenopathy rates in serology-based groups. Note the low rates of VAHL in patients with negative serology result. Lower row: Note the significant higher positive serology rate in patients with VAHL on imaging. All-PET group refers to all patients with hematologic malignancy that underwent [18F]FDG PET-CT after BNT162b2 administration. PET-2 group includes those received the first and booster vaccine doses before imaging a: a statistically significant 
difference of no VAHL rates was found between negative serology and low titer groups; b: a statistically significant difference of no VAHL rates was found between negative serology and high titer groups; c: a statistically significant difference of no VAHL rates was found between low titer and high titer groups; d: a statistically significant difference of grade 1-2 VAHL rates was found between negative serology and high titer groups; e: a statistically significant difference of grade 1-2 VAHL rates was found between low titer and high titer groups;

\section{All-PET patients}

PET-2 patients

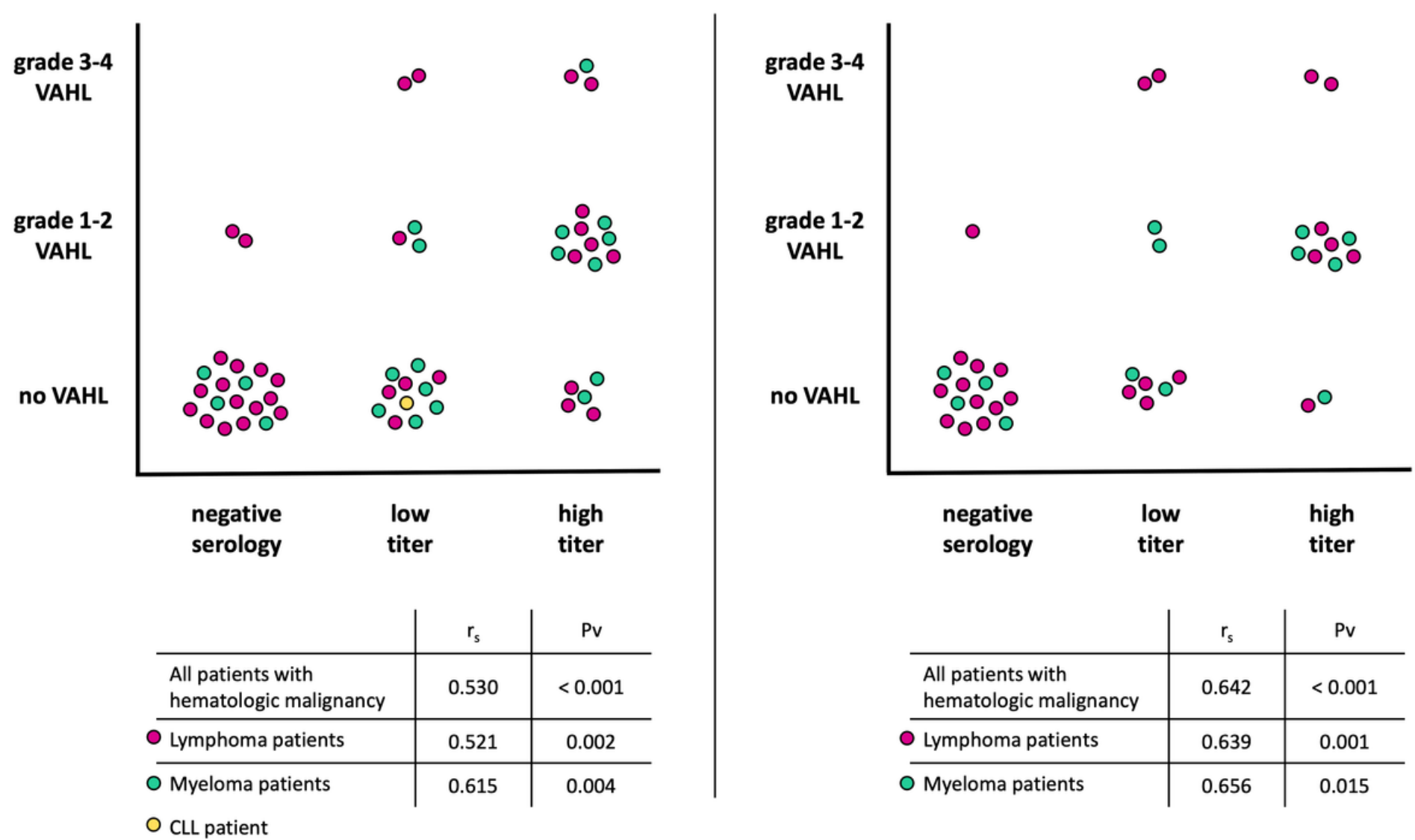

Figure 3

Correlation between serology-based and VAHL-based ranks. All-PET group refers to all patients with hematologic malignancy that underwent [18F]FDG PET-CT after BNT162b2 administration. PET-2 group includes those received the first and booster vaccine doses before imaging 